\title{
Aligning with feminism: Critical autoethnographic reflections of a profeminist heterosexual male teacher educator
}

\section{Suriamurthee Moonsamy Maistry}

Social Sciences Education, School of Education, University of KwaZulu-Natal, Durban, South Africa

maistrys@ukzn.ac.za

https://orcid.org/0000-0001-9623-0078

(Received: 23 April 2020; accepted: 9 September 2020)

\section{Abstract}

In the last two decades, education scholarship has made significant progress in advancing the feminist social justice agenda with women scholars having been almost entirely the drivers of this movement. Women scholars in teacher education have been successful in establishing and consolidating this disciplinary field of study quite firmly in the teacher education curriculum. Despite this, many forms of oppression, including domestic or intimate partner violence and sex- and gender-based violence, continue to plague South African universities and society in general. The current COVID-19 pandemic's mandatory home confinement restrictions have further exacerbated the conditions for individuals likely to experience domestic violence. Men have been relatively silent and inactive in this social justice project. There is also limited extant scholarship that addresses the role that profeminist men might play in this social justice enterprise. There is also little work that attempts to understand the level of sophistication with which men understand feminism, determine with which feminisms men might align themselves, and the accountability and responsibility that might come with assuming certain positions. In this critical autoethnographic piece, I engage with the questions of how critical pedagogical encounters in a teacher education course might serve as disruptive devices that trouble stubbornly resistant gendered socialisations. I draw on my experiences as a teacher educator as I struggle to locate and identify my own profeminist positionality and the tensions this presents. I contemplate the poststructuralist caution about writing (my)self into a text given that the writing self is an evolving/changing self. I reflect on my attempt to disrupt obliviousness as I contemplate the prospect of self-disclosure as a point of entry for profeminist men's praxis in a teacher education programme subscribed to by young men (and women) deeply socialised in a patriarchal history and culture.

Keywords: gender-based violence, critical autoethnography, feminism, pedagogy 


\section{Introduction}

In this paper, I contemplate as a heterosexual male teacher educator, the role I might play in aligning myself with the fight against different forms of gender-based violence in South Africa in my work with pre-service and practicing school teachers in a teacher education course. While violence is not peculiar to South Africa and that people subscribe to violence to assert dominance to resolve disputes is a universal social issue, in South Africa violence against girls and women has become normalised and this normalisation demands disruption as Graaff and Heinecken (2017) have argued. Evidence from the South African context suggests that much of this violence against girls and women happens in homes (Kempen, 2019a) in schools (Bhana, 2018) and on university campuses (Singh, Mabaso, et al., 2016; Singh, Mudaly et al., 2015) with boys and male teachers as pre-dominant perpetrators (Beninger, 2013; Taole, 2016). Violent performances of hegemonic masculinity are of distinct behavioural concern for schools with some activists calling for school-based interventions that become integrated as an essential element of the curriculum (Bhana \& Mayeza, 2016; Rasool, 2017), an imperative that I have taken up in the curriculum I constructed for pre-service and in-service teachers. Violence in schools is not always unidirectional (male-on-female); girl-on-girl violence is not uncommon. As a way of securing economic resources, it is an outcome of pervasive socio-economic inequality that besets many poor South African schoolgirls as Bhana (2008) has noted. Also, there is a misapprehension that girls-only schools are safer havens in being free of violence. On the contrary, sexuality, race, and ethnicity are implicated in violent femininities in such schools (Bhana \& Pillay, 2011). While my concern in this paper is with male-on-female violence, I am mindful of Shefer's (2016) caution that crude male-female binarism is unhelpful since it feeds a victim/agent binary that simply reproduces "gendered, classed and raced othering practices and discourses" (p. 211). Campbell and Mannell (2016) have argued that we have to move beyond man-woman and victim-agent binaries towards understanding women's agency as distributed, which necessitates an alternative to current policy and intervention strategies.

I am acutely aware of my own cisgender framing as proper man and Butler's (1990) challenge to the hegemonic heteronormative matrix, a discussion of which follows later in this paper. I reflect on how I continually attempt to unlearn my own learned prejudice and that even the invocation of the construct of myself as profeminist might well be regarded as a contested signifier (mis)aligned with radical feminism's mission to eradicate patriarchy as Burrell and Flood (2019) have warned. I do, however, attempt to engage the notion of selfdisclosure as a first pedagogical step as I broach the subject of gender as a social justice issue in the economic education programme I teach. Profeminist men's activism dates back to the eighteenth and nineteenth centuries (Burrell \& Flood, 2019). The engaging men's movement has, however, not reached a critical mass. Efforts by men as they relate to eradicating genderbased violence have been marginal, sporadic, and inconsistent and have not proven to be sustainable. Flood (2011) has reminded us, however, of "a growing consensus in violence prevention circles that to end this violence, we must involve and work with men" (p. 359). 
Recent revelations about vicious sexual abuse inflicted on high profile female celebrities at the hands of powerful men in the Hollywood film industry, triggered widespread reaction and unprecedented social media networking. It drew attention to the pervasiveness of gender abuse perpetrated by supposedly respected and trusted household names like Bill Cosby and Harvey Weinstein. In South Africa, the conviction of Oscar Pistorius for the killing of Reeva Steenkamp in 2013 was a high-profile, politicised case that drew widespread condemnation (Shefer, 2013). These revelations reveal the tip of the proverbial iceberg; this phenomenon continues to be played out in all spheres of society. There is also little faith in the ability of the South African police to respond effectively or to intervene in cases of domestic violence in this country (Govender, 2015), let alone showing sensitivity to people identified as queer (Müller, 2019).

The spate of violence against women (male-on-female violence) under home confinement because of COVID-19 restrictions as of March 2020, and the brutal murder of 28-year-old Tshegofatso Pule, who was stabbed and hanged from a tree in Johannesburg, is a reflection of the brazenness with which these atrocities are committed. It has sounded alarm bells with various constituencies advocating for measures to rid society of this scourge. Such calls are not new (Kempen, 2019b). Propositions have been made in the recent past for re-engineering strategies for ensuring that victims have access to resources that ease reporting especially given that the processes for data capture of sex- and gender-based violence often compromise the safety of victims who may be subject to further grievous risk that comes with such reporting (Davis \& Meerkotter, 2017).

Despite relatively vocal local (16 Days of Activism) and international awareness campaigns (\#MeToo), there does not appear to be enough impetus to sustain the intensity of such campaigns; sex- and gender-based violence continues unabated. Sadly, the project of addressing gender-based violence has frequently been used as a political weapon as evidenced in recent South African parliamentary debates on the State of the Nation 2020. Male political leaders brazenly accused each other of gender-based violence. Of concern is that the intention was not to draw attention to this scourge and offer suggestions about how society ought to deal with it; it was, rather, about scoring political points and discrediting it, a display of toxic masculinity with no attempt at disguise. It raises questions about the authenticity of the articulated political will among South Africa's male political leadership. This was clearly not part of a genuine concern for the plight of women but unashamed political grandstanding. While Cyril Ramaphosa, South Africa's president, (and many others) have labelled gender-based violence the parallel pandemic to COVID-19 that afflicts the nation, there is longstanding scepticism as to the state's genuine political will to move beyond rhetoric and eloquent policy (Kempen, 2019b).

Gender-based violence is not a new phenomenon and the theorisations of its occurrence are multiple. It has been a deplorable feature of societies around the world since time immemorial. Grosfoguel (2013) has argued that gender-based violence might well be explained in relation to the self-ascribed epistemic privilege accorded to the western man and has its roots in early colonialism's femicide-the mass burning of women activists in Europe. 
Colonialism's complicity in gender discrimination is well articulated by Lugones. While acknowledging the work of Anibal Quijano (2000) and his theorisation of the colonial matrix of power, Lugones (2016), in an insightful critique, argues that the colonial matrix of power is a somewhat limiting heuristic for understanding the complexly layered dimensions of power that coloniality inscribes, especially as it relates to the intersectional peculiarities of colonised women. The gendered experiences of colonised women might be wholly different from those of the western Eurocentric coloniser woman (Anzaldúa, 1987). In essence then, the complexity of gender as construct renders it powerful yet challenging to apprehend in any universally coherent fashion.

Almost three decades ago, the UN General Assembly Declaration on the Elimination of Violence against Women (1993) was crafted. It represents an internationally recognised framing of "violence against women" as "any act of gender-based violence that results in, or is likely to result in, physical, sexual or psychological harm or suffering to women, including threats of such acts, coercion or arbitrary deprivation of liberty, whether occurring in public or in private life" (UN General Assembly Declaration on the Elimination of Violence against Women, 1993 p. 2). Of serious concern is that gender-based violence has escalated and, since it recurs with alarming consistency, it has become an intractable and enduring challenge facing contemporary South African society despite improved legislation (in South Africa), increased activism through media (including social media), and awareness programmes of various kinds. Different programmes are guided in terms of varying degrees of explicitness regarding the specific gender theory or strain of feminism being invoked. This is a particularly salient point since it points to the dilemma facing intervention programmes in determining programme outcomes and the strategies for their attainment given that the theoretical resources from which they can draw is so rich, extensive, and varied. Even so, many interventions are narrow (Campbell \& Mannell, 2016) and bereft of coherent, theoretically-based gender principles (Jewkes et al., 2015).

\section{Negotiating the terrain of feminisms}

The field of gender research and gender theory is dynamic and replete with contestation (Jakobson, 2014). It is beyond the scope of this paper to attempt a comprehensive synthesis of this highly contested field, a field that Lorber $(2017$, p. 7) described as characterised by "continuities and discontinuities." Of importance, though, is that different feminist theories have certainly advanced the gender social justice project in different ways. As can be expected in any contested field, divergences breed robust debate and the development of rigorous theory.

Several scholars have attempted to categorise the field of gender related work and the multiple approaches to understanding the world of gender. Lorber, (2017, p. 16), for example, addresses the gendered social order as being comprised of, first, gender reform feminisms (1960s and 1970s) or second-wave feminisms that include liberal feminism, socialist feminisms, and development feminism. Second, gender resistant feminisms emerged from a realisation by women that "sisters had no place in any brotherhood" and that in all spheres of 
economic, religious, political, and social life, inequities remained steadfastly pervasive. This spawned radical feminism, lesbian feminism, psychoanalytical feminism, and standpoint feminism. Lorber's third category, gender reform feminisms include multi-ethnic feminism, men's feminism, social construction feminism, post-modern feminism and queer theory, poststructuralist feminism.

\section{About seeking inspiration from Judith Butler}

Arguably the most profound departure from mainstream thinking and a seminal piece that has influenced feminist thought in the last three decades is that of Judith Butler's Gender Trouble (1990). Its appearance marked a distinct critical moment in feminist work that stemmed from the shift in the understanding of gender as complex and psycho-socially constructed and beyond the physiological male-female binary. Butler contests the notion of woman as a gender category. She suggests that gender is implicated by, among others, key structural fixities such as social and economic class, sexuality, culture and ethnicity. As such, the project of understanding women's subordination has, of necessity, to consider the intersectionality of this complexity.

Butler's contribution to the evolution of non-normative gender theory with her seminal theorisation of queer theory has particular resonance for this article. So-called deviant sexualities, like normative gender identities, are essentially social constructions. While Butler recognises anatomical differences, she contends that biology is structured by gender norms and not vice versa, arguing that due cognisance should be taken of how discursive practices and legal signifiers accord importance to somewhat random biological differences that cast the male and female prototype, tightly circumscribing what counts as normative and deviant behaviour. Institutionally defined norms activate the body. The norm-invested body is also formed and shaped by the norm. She further argues that the "conflation of gender with masculine/feminine, man/woman, male/female ... performs the very naturalization that the notion of gender is meant to forestall" (Butler, 2004, p. 43) As can be expected, perceived deviations from the norm are likely to be met with sanction.

Given that Butler's theorisations have had a profound impact on contemporary feminist thinking, this brief exposition of the main tenets of her feminist intellectual project is necessary since it informs the later discussion of what pedagogy we might construct from Butler's conceptualisations. In the first instance, Butler refutes the notion of any fixity or certainty of woman as a construct, arguing instead for relinquishing socially (and politically) imposed binary categorisations of proper man and proper woman. She suggests that such rigid ascriptions serve only to further perpetuate sexism, in due compliance with the "legitimating practices of identity formation ... within the matrix of gender norms" (1990, p. 70). In her view, gender identity formation is in a constant state of flux, contingent upon what presents in the social contexts we habituate, perpetually moving between strains of femaleness and maleness, as each context dictates. In contrast to a traditional understanding of our behaviour as internal or intrinsically driven, Butler suggests that, in fact, our performances of gender are the result of predefined and anticipated authoritative social scripts 
which we repeatedly enact, a process of fictive manufacture. Butler's theorisations are certainly subject to critique especially as they relate to the (lack of) resonance with the experiences of subjects in the Global South, the peculiarities of which are well articulated by theorists like Anzaldua (1987) and Lugones (2007).

Butler's work is pedagogic since it offers a heuristic for understanding how gender is learned and inscribed. Importantly, it opens the possibilities for a dismantling and unlearning. In many ways, my gender performance has been precisely what Butler described as an enactment of predetermined practices that have long been established for males like me, fulfilling or materialising obligatory norms defined by the binary, socially constructed sex markers. Through this paper, I attempt to understand gender in its broadest critical, decolonial, feminist sense (Lugones, 2016). I also recognise violence in all its manifestations, beyond overt physical aggression. Flood (2011) notes that the proclivity for violent behaviour by men is related to the "constructions of masculinity" (p. 359).

\section{A profeminist cue}

This paper is not meant to be a praise-song or any attempt at romanticising my practice. If anything, it attempts to capture the frailties, discontinuities, and contradictions that heterosexual males (like myself) are likely to experience as they undertake this kind of work especially given that the world of feminisms is vast and often confounding. In an insightful article entitled "Which Feminism? Dilemmas in Profeminist Men's Praxis to End Violence Against Women”, profeminist male practitioners, Burrell and Flood (2019) signal the dilemma facing profeminists as it relates to working out which feminism to be accountable to. They note that there are "multiple, incommensurate feminisms, with radically different and incompatible ideologies and practices" (p. 4). Profeminist male advocates, in negotiating this dilemma and in constructing deliberative efforts to curb violence against women should, in the first instance, ensure that profeminist work is guided by theory. Burrell and Flood (2019) offer what they term rudimentary principles as minimum standards for profeminist work towards the elimination of violence against women. They note that as profeminist men,

we strive to enact transformations towards gender justice in our personal lives, in the lives of other men and boys and in society as a whole ... account about our practices . . . take on the responsibility to learn, and to change ourselves and other men in order to live in more gender-equitable ways . . listen and learn from the diversity of women's experiences and engage critically and reflexively with a range of feminist theories and ideas ... consult with feminist women ... critically reflect on ... the extent to which the work being carried out is effective . . . we address different forms of men's violence against women ... consider (how) we are also personally implicated in, and privileged ... we recognise the importance of . . women-only spaces being prioritised and playing a leading role within struggles to end men's violence against women and gender inequality ... (which) means working to counteract the potential for men to dominate or 'take over' such efforts. (p. 12) 
While these guidelines are not meant to be all-encompassing, and certainly not the only ones, they do, however, offer a critical base to which novice male gender activists might subscribe in order to contribute to and advance both theory and practice as they contemplate the complex agenda of engaging men on gender-based violence against women and gender inequality. This then raises the question about how to construct an appropriate pedagogy and what theoretical and conceptual insights might apply. Using (my)self as a point of entry when teaching about learned gender discriminatory behaviour is an approach to pedagogy that I have been experimenting with in recent times. The theoretical weight behind disclosing the fragile and vulnerable self as pedagogical resource is somewhat slight and even confounding in the face of contemporary pedagogical theory that suggests a powerful knowledgeable pedagogue with firm authority over the pedagogical and disciplinary knowledge that she or he wishes to teach her or his students. I do, however, draw on two key theoretical concepts to help shape a conception of how this might be understood and applied. Liminality and dissonance are, for me, powerful heuristic constructs worth considering for this kind of pedagogical work.

Liminality, a construct theorised by Victor Turner in 2017, (drawing on the seminal work of Arnold Van Gennep), refers to a transitory space between not knowing and getting to know. The etymology here is the Latin word limen, a threshold akin to the base of an entranceway one has to cross to gain access to the (social) space one wants to enter. The subjects find themselves in a state of in-betweenness, in a fluid and uncertain milieu in which they have not quite earned the right of passage or crossed the threshold towards the goal of full recognition by pre-existing members of the yearned for social space. This socio-discursive space may not be easily accessible and is likely to be well patrolled by gatekeepers who judge whether the aspirant newcomers meet or have acquired the necessary credentials to engage with credibility on the issues of the field. Szakolczai (2009) claimed that novice aspirants endure anxiety, personal conflict, and a poor sense of self in this transitional phase since they doubt their own potential to master the benchmarked competences. Furthermore, they are likely to experience a traumatic separation from their existing identity.

In negotiating

this rite of passage, they are likely to show obedience and humility and simply fall in line with the expected new conduct and behaviour. During this phase, individuals are likely to engage with concepts and new issues superficially, mimicking expected behaviour - their understandings remaining incomplete or partial, causing discomfort and emotional trauma. (Maistry, 2017)

Their experience reflects a dissonance, an emotional (and cognitive) state in which the subjects simultaneously hold contrasting and contradictory perspectives on an issue. The duration of this liminal phase and its consequent dissonance varies. If the subjects choose to forego the aspirant identity, then they return to their original identity and restore their harmony. If the aspirant subjects persevere, they could well remain in the liminal stage for the rest of their lives if the co-ordinates of the aspired for identity remain elusive or are constantly shifting. The concepts of liminality and dissonance are useful for analysing and 
assessing my aspiration for identity as a profeminist man since they speak cogently to the journey I have chosen.

\section{A brief description of the programme I teach}

This postgraduate course (at Honours level) has been designed for practicing teachers of commercial subjects. One of the objectives of the course is to provide an opportunity for students to reflect critically on the nature of the discipline that they teach at school. As we know, school subjects like economics, business studies, and accounting have firm roots in neoclassical economics, are underpinned by contemporary neoliberal principles, and accept the current models of western capitalism as normal. Neoliberal and neoconservative policies that discredit the notion of a welfare state and social security payments disregard the fact that women (in both developed and underdeveloped countries) are the main recipients of such transfer payments. Historical hierarchies as they relate to class and gender are accepted as normal outcomes of capitalism, the theorisation of which has its roots in the work of feminists like Chodorow (1978) in the seventies. The neoliberal canon has, however, shown little consideration for its gender discriminatory economic policy outcomes. Undergraduate degrees in the field of commerce seldom (if ever) contest the nature of level one economics, for example. A more or less standard curriculum exists throughout the world. Students and teachers of economics are rarely provoked into contesting the nature of the discipline. For example, the South African Curriculum and Assessment Policy accepts neoclassical economics as valuable and trusted knowledge.

In the postgraduate economics education course I teach, my intention is to provoke students to challenge the basic tenets of commercial knowledge. I attempt to integrate a strong social justice dimension into the programme. An aspect of the broader social justice dimension is a focus on gender in the economic and social world. The hope is that these advanced students (many of whom are currently active teachers) will engage with gender issues in their own classes and will use the curriculum as a site of contestation and critique. To this end, I harness powerful literature that presents alternative ways of understanding the world of economics. This has to be supported by a carefully considered pedagogy. As a point of entry, as teacher educator, I deliberately and consciously adopt the position of vulnerable self. I will present an analysis of how and why I apply this pedagogical frame in a discussion that follows the narrative vignettes below.

This university programme is run in the province of KwaZulu-Natal, South Africa. As such, it is historically comprised of students of the predominantly indigenous African population, with a few Indian students in some years. The three vignettes below represent the variation of ideal types of male students who have presented in my classes over the last decade. These archetypes are useful for analysis purposes and while these evocative descriptions are meant to represent characteristics typical of these groups, they are not to be understood as representing individuals locked in fixed, rigid categories since much blurring is at play as participants move between and within each category. These derivations emerge from three 
key gender-related questions that I pose in my Honours class. For each, I place verbal emphasis on the italicised word and follow each with a question.

a) What are the attributes of a man?

b) What are the attributes of a good man?

(The third question is directed at the males in the class.)

c) Assuming you are heterosexual, are you likely to marry or partner a woman who earns a higher salary than you do? Why

As can be expected, these questions trigger animated discussion. The third question creates much angst and dissonance. While there are variations in intensity and conviction, the recurrent overwhelming response is an emphatic rejection of the possibility that the relationship could work. Issues of leadership, control, final decision-making, power and even obedience surface as key areas of contestation that oppose such an arrangement. The responses are unadulterated, unfiltered, honest, and brazen and they depict the degree of concretisation of gendered stereotypes that are deeply embedded in these male students; the pervasive power of the masculine in contemporary (South African) society is made manifest (see Graaff \& Heinecken, 2017; Kimmel, 2014; Morrell et al., 2013).

\section{Vignette 1 (Archetype A): The purist male chauvinist who embodies toxic hegemonic masculinity}

These are authoritative males who derive their authority exclusively from being male. They show awareness of supposedly superior physicality and the power that comes from this physical strength. They are demanding, they constantly denigrate women using flawed arguments, they make disparaging comments about women, and are patronising. Openly confrontational and prone to be publicly vindictive, egocentric, stubborn, they believe that their point of view should be what counts and what should hold and they seldom budge from their positions. Insecure and defensive when shown up, they are aloof. They may be intellectually strong and this leads them to believe that they know more and are therefore better than those who know less so they use this to intimidate even in a congenial way.

These men often use (African) culture as the main rationale for the position they take. They feel obliged to uphold a strong patriarchal tradition as if they were the guardians responsible for the culture's perpetuation. They use this to legitimise their perspectives on the role of men and women in society and continue to be strong advocates for the belief that men are the superior sex. They openly and unashamedly declare their gender prejudice and are openly homophobic with little tolerance and patience for non-normative gender discourses.

Vignette 2 (Archetype ' $\mathrm{B}$ '): The congenial chauvinist who is amenable to engaging in superficial alternative discussions about the assumed superiority of men

These individuals reluctantly engage with issues of gender equality and participate at a superficial level. They acknowledge grudgingly that gender equity is a matter of concern, and continue to enjoy the power and privilege that comes with being male. Less aggressive than 
the purist chauvinist, they also hide behind culture. They recognise the potential of women but are uncomfortable with what this might mean for them and want to remain in control although they are prepared to accept a marginal relinquishing of power and authority. They appear somewhat embarrassed to be recognised and identified as caring about gender issues.

\section{Vignette 3 (Archetype 'C'): Secure, emancipated males}

These authentic individuals with their deep sense of respect for humanity in general are particularly aware of their maleness and the assumed authority and power that is associated with their biology and the social construct of maleness. They live the gender equity project through their words and actions and are not threatened by strong men or women. They challenge the two archetypes above but prefer not to engage in open verbal combat.

In passing, I must mention that in my more than two decades of working with higher education students, I have encountered just two individuals who fall into this category.

I acknowledge that the illustrations above are not definitive nor fully comprehensive and that they are subject to contestation (which this paper attempts to invite). I am also aware that this particular pedagogic move might well reify the male-female binarism that Butler (2004) and Shefer (2016) have cautioned against. I have, however, found that it presents as a somewhat safer brokering and leverage mechanism to enable me to proceed towards more nuanced understandings of non-normative gender. I have discovered, through trial and error, that an important point of departure for this kind of work is to begin with the self through a critical introspective account of my own heterosexualness and masculinity which makes me, inevitably, an historicised oppressor standing on male privilege except that this comes for me with an attempt to confront such privilege as advocated by Jackson and Mazzei (2008). I draw on the tenets of Boylorn and Orbe's (2014) notion of critical autoethnography and Gannon's (2006) insights into the tensions that poststructuralism presents in writing the evolving self. I reflect on my practice as teacher educator as I attempt to integrate genderrelated social justice issues into the curriculum I conceptualise. Although this has been a feature of my teaching programmes for more than a decade, I continue to experience varying levels of frustration and only marginal success as I attempt to create and implement a pedagogy that might lead to substantive disruption. The classic poststructuralist position holds that any attempts at discerning a substantiveness of any disruption, serves only to illuminate the extent of its unsubstantiveness. I have come to realise that even marginal shifts in attitude have to be valued and treasured since they indicate, quite powerfully, the enormous size of the challenge that the gender project faces.

\section{A methodological note}

[C]ritical autoethnography is a fitting research method that allows autoethnography researchers to use their personal experiences and sympathetic eyes to analyze and critique injustice pertaining to educational contexts. (Marx et al. 2017, p. 1) 
Autoethnographic scholarship is gaining traction in the South African higher education sector and is proving to be a compelling approach to research in the country's multifaceted sociocultural context (see Pillay et al., 2016; Pithouse-Morgan et al., 2017).

Autoethnography has particular appeal as pedagogic method for harnessing student experience as a resource that might enable the acquisition of desired course objectives (Barr, 2018). Central to this approach is the autoethnographer's apprehension of autoethnography's language of description, its conceptual repertoire, and its discourse which, in the Foucauldian sense, entails more than language as signifier of meaning and might include ways of thinking, speaking, and acting in congruence with its (evolving and emerging) tenets which, for the budding critical autoethnographer (like myself), might appear tantalisingly elusive yet powerfully useful.

Berry and Hodges (2015) have asserted that (personal) vulnerability, reflexivity, and empathy are powerful conceptual apparatuses for the study and application of critical autoethnography in undergraduate writing courses. The concepts of vulnerability and reflexivity have particular salience for this paper since they compel the autoethnographer to move beyond mere storytelling. Jones (2016) suggested that critical autoethnography invokes "clear and powerful theoretical frameworks for understanding how stories help us write into or become the change we seek in the world" (p. 1). It may also offer an approach to deal reflexively with personal offenses that one may have committed (Adams, 2017). As a research and pedagogical strategy, critical autoethnography's imperative towards reflexivity enables the strategic use of personal narratives to engage with broader social justice issues at play in society (Reed-Danahay, 2017), as is the case that I report on in this paper.

Ellis and Bochner's (2003, p. 739) photography metaphor of "wide-angle lens" suggests a looking outward by drawing attention to the socio-cultural dimensions of personal experience, as a prelude to an inward look. This might entail a critical introspection, akin to Deleuzian "lines of flight" (Deleuze \& Guattari, 1987, p. 225) in which the possibilities for disruption of the self as well as the cultural normatives become possible. These insights have appeal as outlined in the work of Mitchell (2016) who offers useful insights for the autoethnographer's positionality as she contemplates what might be productive and generative in relation to both pedagogy and social change. I am, however, mindful that claims to, and aspirations for, the measurable productive and generative outcomes of research might be counter-intuitive to the seminal tenets of critical autoethnography, an approach that might well fall foul to a positivism of sorts.

The allure (for me) of critical autoethnography is, arguably, its defining feature which is its potential to integrate autobiography, ethnography, and critical pedagogy into a methodology that affords the researcher a milieu within which, for me, his complicity as historically situated researcher (and self-recognition as oppressor) can be intensely interrogated (TilleyLubbs, 2016). The writing of the self is always about a vulnerable self. Critical autoethnography invites "powerful intellectual and political commitments of critical theory" (Jones, 2016, p. 228). I am wholly aware of Gannon's (2006) caution that 
the paradox of poststructural autoethnography is that although autoethnographic research seems to presume that the subjects can speak (for) themselves, poststructural theories disrupt this presumption and stress the (im)possibilities of writing the self from a fractured and fragmented subject position. (p. 474)

Poststructuralist autoethnography has to, of necessity, trouble the speaking self so as to problematise the self and "to produce evocative, therapeutic stories" while simultaneously recognising the limits of the autoethnographer for understanding the self and the other (Jackson \& Mazzei, 2008, p. 300).

Foucault's genealogy has distinct appeal for this kind of introspective account. It allows us to discern how contemporary regimes of truth have come to be. It enables a reflective problematisation of the present with a view to contemplating a transforming future. In essence, genealogy views the present as contingent (Foucault, 1979). In assessing how the present came to be, we are better positioned to envisage alternatives for the future as we consider how the unconscious ways in which we think and act have come to be. We reflect on what has shaped and informed the episteme and current discursive formations and how unconscious rules about gender have become so deeply engrained in our thinking that we are hardly aware of them. Importantly, we may engage with how particular knowledges have been constructed that realise the contemporary power/knowledge matrix and its subsequent governing of thought, practice, and how power has produced and normalised certain behaviours and actions. Foucault's application of genealogy in The History of Sexuality has particular resonance since it illuminates how sexuality is constructed and how a heteronormative sexuality gained traction and currency to resemble a truth discourse of naturalness, kinetically producing a self-censuring, self-scrutinising, and self-regulating subject.

In an interesting reading of Foucault's notion of writing the self, Gannon (2006) describes this time-old tradition of aspiration for ethical subject development through writing to release, as cathartic growth. In Foucauldian terms, it entails a self-care through a selfknowing through tangible linguistic expression. It might entail a dismantling of the self, a metaphorical dismembering of the body with its feelings and cognitive repositories historically fashioned in sociocultural spaces. Gannon reminds us that "the authority for the story begins with the body and memories ... at the scene of lived experience" (p. 478). She argues that "the historical 'I' and the presently writing 'I' are not the same psych-social body" requiring the autoethnographer to "destabilize the authority of the self who writes and knows himself or herself as a discrete and autonomous subject" necessitating a "scrutiny, revision, and compulsory confession" (p. 479). This is a pedagogic strategy that I attempt to employ as I engage with the issue of gender discrimination and gender-based violence with my students.

As teacher educator, I invoke personal testimonio as necessary first stage in attempting to create the conditions and opportunities for exposé and revelation so as to facilitate deep connections through conversation that is not bounded by epistemological circumscriptions of rationalism associated with the disciplinary conventions of economics. I attempt a process of 
candid divulgence, not simply for the purpose of soliciting confessions from my students, but with the aim of getting them to understand how to enter a fluid, dynamic, and productive pedagogic space in which to contemplate their subjectivities and to be comfortable doing so. I invite narrations - oral, written, and/or online — in a context that fosters deliberative narrating and listening. As can be expected, invoking the mind, body, and spirit is in tension with the training that my students (disciples of the economics discipline) have received in their undergraduate courses. I attempt to help my students shift from rational (economic) problem solving using hard data (quantitative analyses) and the search for definitive answers towards understanding the (economic and social) world as uncertain and constructed in ways that contribute to oppression of various kinds and of women in particular. This pedagogic space has to be based on patience as we deal with contradiction and creativity to allow for the negotiation of new meaning that embraces the liminal as a necessary and ongoing condition.

I am very aware that in my self-disclosure that follows below, my reference to intimate (and extended) family and acquaintances, although not named or identified with any specificity, does present me with some trepidation for ethical reasons. I draw on my lived experience with this cast from whom I learned to perform. There is a precariousness about this kind of storytelling as Ellis (2007) rightly points out. Her notion of relational ethics is important since it suggests that despite the noble intentions of the storyteller, the writer (me as autoethnographer in this instance) is always invested (as academic and activist) and that actors implicated in the stories we construct, even when representations are positive, may not always agree with the nuances and embellishments that we introduce. The narration that I present below draws particular attention to gender prejudice. As such it implicates by default and is likely to be unsettling for the implicated (even if they are not identified). While researchers (autoethnographers in this instance) have to work within generally acceptable ethical principles (Beauchamp \& Childress, 1979), the extent to which such principles grounded in the biomedical field have resonance in the socio-cultural research space is a moot point (de Castro \& Valero, 2018).

\section{Testimonio as pedagogical tool}

Testimonio is a pedagogic practice that has its genesis in oral cultures and has been applied effectively by Chicana/Latino feminists in social projects aimed at exposing oppression so it has enormous potential for disrupting contemporary hegemonic discourse (Cervantes-Soon \& Carillo, 2016). It is an approach to teaching that contests traditional Cartesian rationality and its associated patriarchal leanings by "centering the mind, body, spirit, and political urgency in teaching and learning" (p. 291). Personal testimonies can be viewed as agentic resources with the potential for confession and reflection, moving beyond just dialogic teaching. Cervantes-Soon and Carillo contend that

[t]estimonio offers the ability to critically historicize the body, mind, spirit and experiences, to connect them to larger social structures and thus serve as a point of departure in the articulation and exchange of theory in the flesh. (p. 292) 
At the heart of this pedagogy is the sharing of personal narratives by both teachers and students with the view to building solidarity among them in the target social justice project.

\section{About a non-normative pedagogy}

The classic poststructuralist position of the elusiveness of an absolute reality as it relates to gender identity as argued by Butler (2004), implies contemplating a non-normative pedagogy of sorts. It beckons and invites a pedagogy that might be non-rational, eclectic, unconventional, and one whose outcomes cannot be predetermined. This has been my experience of running a programme that seldom delivers as per programmed instructional intent. The inability to apprehend a firm reality is likely to be somewhat disconcerting (for students and even external examiners seeking to establish whether programme outcomes have been attained or not).

Where then and how might a pedagogic disruption be conceived? In the section that follows, I tentatively present my attempt at this arduous task as I contemplate the notion of selfdisclosure as the first strategic pedagogical move in broaching gender equality issues in a context where unbridled oblivion reigns.

\section{Self-disclosure: Modelling ownership of learned discriminatory behaviour}

South Africa emerged from a system of apartheid in 1994, a system characterised by racial hierarchisation in which the minority white population held non-whites in subjugation, denying them both economic and political rights. In my early days as an anti-apartheid activist teacher and later teacher education activist, my eagerness to want to change the economic and social world resulted in my adopting a somewhat aggressive approach in dealing with people whose views were contrary to mine. As a school teacher of economics, I taught actively about resistance politics through the lens of political economy. I strongly advocated for an ideology that was anti-discriminatory since I firmly believed that antiapartheid propaganda was good because it served a socially just cause. As can be expected, forceful anti-apartheid pedagogy was likely to be received without much contestation from the non-white learners whom I taught at that time. Teaching about gender prejudice to advanced Honours students, however, presented me with peculiar challenges.

I quickly discovered that an aggressive, accusatory pedagogy was not going to be effective especially with Archetype 'A' male students who already had well-cemented ideas and defences for the positions they held. In fact, an aggressive and accusatory pedagogy served only to further entrench the views I was attempting to disrupt. A naming and shaming pedagogy simply created an unhealthy and risky classroom environment. Archetype ' $A$ ' males reacted with aggression. In one year, an archetype 'A' male openly declared that he would write up his assignment (essay) in a way that I (the assessor) would find appealing (since he would say all the right things) so as to achieve a pass score for the course. He was, however, quite clear that he did not subscribe to the gender equality value system I was 
advocating in the course. There have also been instances where male students have walked out of class, declaring that this nonsense was not for them. I came to realise that an open, confrontational approach in my classes was not useful; it was, in fact, counter-productive since discussions between me and archetype ' $A$ ' males and other students in the class became heated. While a few vocal and confident female students stood their ground, other female students found the situation quite unsettling and threatening and later some commented that aggressive male reaction on gender issues was a regular normal occurrence and that such encounters seldom ended with any concession on the part of such males. If anything, the women students believed that such public confrontation made them feel vulnerable to further verbal abuse later. My naivety was blatantly apparent, especially as it related to the limitations of critical constructivist pedagogy that I so believed in and wanted to practice. It became clear that such theoretical resources had limited currency in this kind of pedagogic arena and with this kind of student profile.

I discovered a pedagogic move that presented as far less threatening and this was to narrate aspects of my own gendered socialisation as a resource for deliberation in the hope that it might provoke or initiate a discussion from the diversely socialised subjects in my class.

\section{My early gendered socialisation}

I was born in the mid-1960s into a segregated community of second-generation Indians who were brought to South Africa as indentured labourers (a British euphemism for slaves). It is clear to me that the social (and economic) world in which I was raised and socialised had shaped my worldview in particular ways. My ancestors (in India) hailed from a hierarchical society in which economic and social class discrimination had been reified through the caste system. Patriarchy was (and still is) a defining feature of Indian society. Apartheid's mandatory separation (geographic, social, cultural, and economic) of the races meant that much of my learned behaviour was from within a fairly tightly insular Indian frame of reference as Govender (2018) has pointed out. There is much literature that analyses Indian society's reverence for the boy child and the subservient, non-aspirant status of the girl child (see Bhasin, 2013; Narayan, 1997). Even among the lowest of social and economic classes, the gender hierarchy is a taken-for-granted norm. While South African Indian society might have shifted somewhat, especially given the country's constitutional stipulations as they relate to gender discrimination, these shifts have been marginal, and the traditional gender protocol is still largely in place as Bhana and Buccus (2016) have noted. Religion and culture inherited from the motherland is practised largely along the same gendered lines with limited if any contestation of the status quo.

As can be expected, given the prevailing conditions, my learning to be male, to be a man, has been textured and conditioned from my birth, through childhood and adolescence into my adulthood. The typical expectations of males to be leaders in having to assume authority and develop the ability to assert control and exert power over female counterparts permeated naturalised lessons that were freely and easily taught in the South African Indian school of life. I must concede that I was a willing learner who seldom (if ever) questioned this kind of social ordering and I was unaware of the patriarchal dividend (Connell, 2005) I was reaping. 
Willing teachers (both male and female), from my parents to uncles and aunts and from cousins to friends upheld (and continue to do so) this gendered social arrangement. My formal schooling (primary and high school as well as undergraduate study at a University for South African Indians) simply mirrored male privilege that played itself out in South African Indian society and South African society in general. My learned gendered behaviour was thus systemic, normalised, and affirmed and I was on track towards becoming a firm disciple of this normative cult practice.

\section{Unlearning: Towards a new consciousness through confessional tale (an embattled position)}

As a young person I learned to perform all sorts of very problematic behaviours. There are so many; one behaviour of which I am still particularly ashamed that I learned from observing others, was to mock and ridicule people of non-conforming, non-normative genders. The people I associated with (including myself) thought it was fine (and fun) to harass, to insult, and to demean. I later learned how very wrong this was. What I was doing was elevating myself above them as if I were the representation of what was supposed to be right, correct, and perfect. I accorded myself the authority to stand above and judge and voice my disapproval about other human beings whom I saw to be different. Later I began to question what made me better and so perfect and began to question who gave me any power or authority. I came to realise that there was no basis for this kind of prejudice. This was one instance of unlearning (or learning differently) for me.

It is difficult to pinpoint any single trigger that has led me towards a new consciousness. There were, however, multiple critical incidents in my young adult life that led me to question my learned gendered prejudicial behaviour. I must declare upfront that I am not making any claim to be cured of this affliction. The learning to unlearn has been (and still is) an on-going and fascinating process. One of my earliest contemplations of the need for gender equity came out of my own political activist work as a student and school teacher. I was particularly drawn to the teachings of the Freedom Charter, The Black Consciousness manifesto, and early ANC policy. Fundamental to all these was the call for nondiscrimination on the basis of race or gender. I began to reflect on how, within the ANC at that time, racial inclusivity based on racial emancipation was the central ambition of the movement. Gender discrimination remained largely at the level of rhetoric and played second fiddle to the primary quest for a non-racist society. My experience of working in the then banned ANC teachers' union structures and civic association structures made me realise that many of my comrades were not serious about gender equity but were fixated entirely on nonracism. That this may have been the strategic thrust of the liberation movements at that time is arguably a compelling reason for the somewhat marginal progress made with the gender equity agenda. To me, the contradiction became quite stark and I came to the realisation that I had to reflect on how I envisaged the broader social justice project given that the ANC as ruling party (and former liberation movement) constantly traverses a contradictory agenda (see Govender, 2008). 
A second compelling trigger that evoked a meta-awareness of the assumed authority of my maleness came to me when I began my first serious relationship with the woman who has been my wife for just over three decades. She brought to our relationship an assertive, selfassured, confident, yet non-threatening disposition, a disposition that did not aggressively challenge my maleness and my assumed privileged position that comes with being male in the family (and community) in which we lived. We both achieved our teacher education qualifications at the same higher education institution and we began work in the same year. At that time, despite being on the same professional level, she earned a lower salary than I did. We both taught at schools managed predominantly by men. Her experiences of engaging with powerful men and what it felt like to be controlled by male egos and insecurities helped me to reflect on my own behaviour as male that stands on privilege. I must confess that although I have two sisters, I had not paid attention to how the world had conspired and discriminated against them as women. That realisation just did not occur to me at that time.

A third and arguably the most compelling trigger that has accelerated my shifting consciousness about gender discrimination is the life experiences of my two daughters, both of whom currently have occupations in a field (engineering) heavily dominated by males. Gender prejudice in this field is particular acute and is reified on a daily basis. Learning to understand how this assemblage is constructed has been a distinct learning experience for me as I reflect on how I contribute to maintaining (and, I hope, disrupting) the status quo in the spaces I occupy. Raising both my daughters in a patriarchal society (described above) meant that my wife and I, had, of necessity, to adopt a determined against-the-grain approach. It meant defying religious and cultural practices that privileged boys over girls. This meant earning the wrath of family for what was thought of as non-compliance with acceptable behaviour along with their rejection of us as we developed a strategy for managing confrontational individuals (both male and female) who held archaic beliefs about the role and place of women in society. This, as can be expected, remains an ongoing project. The more important project, however, is my personal one, my own journey in the direction of confronting my own learned prejudice and aiming for a sense of integrity and authenticity as I contemplate my cisgender identity.

\section{Discussion and concluding comments}

Butler's (2004) insights were valuable in understanding that gender prejudice is learned and performed in spaces where the director(s) and props work to choreograph predetermined practices. The social classroom is set up for this to happen in an almost natural fashion. Willing pedagogues and learners are active participants but are, in a sense, unconscious. A nuanced understanding of how this kind of learning happens is powerful since it points to the possibility of disrupting the content, pedagogy, and dispositions of the various actors in the social classroom. In this paper, I attempted to show how engaging the disposition of vulnerable self is a powerful technique with the potential for pedagogical disruptions. This approach decenters the teacher as powerful absolute knower and transmitter and recalibrates the power relations between the teacher and learner. Deliberative vulnerability as pedagogic disposition has to be authentic. It emanates from a deep will to alter thinking, a will that 
despite the risks and repercussions for the self, perseveres in its intent in the hope that substantive change in behaviour might be the outcome of the effort. Of course, this approach could be accused of being an attempt at self-cleansing or a confessional for personal conscience appeasement. In applying Foucault's (1979) technologies of the self, using the vulnerable self as resource might be regarded as a productive pedagogic strategy in which the subject reflects on its formation and ongoing construction and reconstruction. It follows, then, that reflexivity as a founding tenet of autoethnography as it relates to teaching and learning is powerful since it suggests a move beyond reflection towards some action of advancing the aspired-for social justice project. I contend, though, that this reflexivity might well be followed by a tentative set of new contemplations for pedagogy. At best, they are likely to be a modest conceptualisation-in-process. Even the (somewhat disparate) theoretical insights drawn on in this piece (Butler, 2004, Foucault, 1979, Turner, 2017, and Cervantes-Soon and Carillo, 2016) to analyse and interpret are experimental so it warrants a tempered claim to the extent of the generative as it relates to teaching and learning.

In pursuing the use of the vulnerable self, it might be necessary to analyse how the self came to the state of vulnerability and, importantly, to discern how the vulnerable self musters the confidence to proceed or, in other words, to analyse the triggers that might move men (like me) out of, and beyond bystander behaviour. I knew inherently that discriminatory behaviour was wrong, but I elected not to make it my business by simply turning a blind eye. Living and socialising with known perpetrators of violence against women (at that time) was (and still is) common practice. Not having the tools for intervention and the absence of good role models are arguably fragile arguments and conveniently construed excuses. My personal experience does, however, point to their degree of plausibility, especially as it relates to my knowledge of the world of gender theory and praxis. Important, though, is that it draws attention to the focus of the nature of interventions that might be useful. Dealing with fear, anxiety, external judgement, and being accountable to the male fraternity are compelling factors with which Archetype ' $A$ ' males require assistance, an area that certainly requires further research. Fear of losing power is unsettling and disorienting to the powerful. Self-disclosure then might entail empathising with the Archetype ' $A$ ' male. Disclosing my own inhabiting of the Archetype ' $A$ ' space, revealing the pressures (and benefits) of remaining in that space might be useful in helping Archetype 'A' individuals to acquire a deeper understanding of how they have come to hold the dispositions that they have, in a non-threatening yet sufficiently disruptive way. How to create a conducive environment for engagement, balancing aggressive and over-assertive approaches with inclusive ones in dealing with Archetype 'A' males is certainly an area worthy of research. It is clear that the practice of calling out the male fraternity and naming and shaming entire groups is not helpful. It is likely to make the males close ranks and feel threatened and might induce a fight or flight response. This raises questions about how to develop healthy expressions of masculinity, how to disrupt what has become known as common sense and generationally transmitted knowledge. We need to interrogate the default defence that is couched as "It's my culture." It also entails unpacking and dismantling the faulty biological and physiological argument and examining the logic that being born with male genitals ascribes to males' automatic natural power, authority and 
wisdom, an argument that is surprisingly still commonplace even among advanced postgraduate students.

\section{References}

Adams, T. E. (2017). Critical Autoethnography, education, and a call for forgiveness. International Journal of Multicultural Education, 19(1), 79-88.

Anzaldúa, G. E. (1987). Borderlands/La Frontera: The new Mestiza. Lute Book Company.

Barr, M. (2018). Autoethnography as pedagogy: Writing the "I" in IR. Qualitative Inquiry, 25(9/10), 1106-1114. https//doi.org/10.1177/1077800418792940.

Beauchamp, T., \& Childress, J. (1979). Principles of biomedical research. Oxford University Press.

Beninger, C. (2013). Combating sexual violence in schools in sub-Saharan Africa: Legal strategies under regional and international human rights law. African Human Rights Law Journal, 13(2), 281-301.

Berry, K., \& Hodges, N. (2015). Naked teaching: Uncovering selves in the reflexive classroom. Journal of Education, 62, 59-84.

Bhana, D. (2008). "Girls hit": Constructing and negotiating violent African femininities in a working-class primary school. Discourse: Studies in the Cultural Politics of Education, 29(3), 401-415.

Bhana, D. (2018). Girls negotiating sexuality and violence in the primary school. British Educational Research Journal, 44(1), 80-93.

Bhana, D., \& Buccus, I. (2016). Blue Lagoon: Race, class, space and the making of Indian masculinities. African Identities, 14(4), 321-331.

Bhana, D., \& Mayeza, E. (2016). We don't play with gays, they're not real boys . . they can't fight: Hegemonic masculinity and (homophobic) violence in the primary years of schooling. International Journal of Educational Development, 51, 36-42.

Bhana, D., \& Pillay, N. (2011). Beyond passivity: Constructions of femininities in a singlesex South African school. Educational Review, 63(1), 65-78.

Bhasin, K. (2013). Understanding gender. Raj Press.

Boylorn, R., \& Orbe, M. (2014). Critical autoethnography: Intersecting cultural identities in everyday life. Left Coast Press. 
Burrell, S., \& Flood, M. (2019). Which feminism? Dilemmas in profeminist men's praxis to end violence against women. Global Social Welfare, 6, 231-244. https://doi.org/10.1007/s40609-018-00136-x.

Butler, J. (1990). Gender trouble: Feminism and the subversion of identity. Routledge.

Butler, J. (2004). Undoing gender. Routledge.

Campbell, C., \& Mannell, J. (2016). Conceptualising the agency of highly marginalised women: Intimate partner violence in extreme settings. Global Public Health, 11(1/2), 1-16. https:// doi.org/10.1080/17441692.2015.1109694.

Cervantes-Soon, C. G., \& Carillo, J. F. (2016). Toward a pedagogy of border thinking: Building on Latina students' subaltern knowledge. The High School Journal, 99(4), 282-301.

Chodorow, N. (1978). The reproduction of mothering. University of California Press.

Connell, R. W. (2005). Masculinities. Allen and Unwin.

Davis, C., \& Meerkotter, D. N. (2017). Exploring the heuristic value of non-personal data for sexual- and gender-based violence research and prevention in South Africa. African Safety Promotion, 15(1), 16-37. https://journals.co.za/content/journal/10520/EJC$82 \mathrm{c} 69 \mathrm{da} 03$

de Castro, L., \& Valero, I. (2018). Ethics education needs more than the four principles: Bioethics discourse in a community of inquiry. In H. ten Have (Ed.), Global Education in bioethics. Advancing global bioethics (pp. 69-80). Springer Cham.

Deleuze, G., \& Guattari, F. (1987). A Thousand Plateaus. University of Minnesota Press.

Ellis, C. (2007). Telling secrets, revealing lives: Relational ethics in research with intimate others. Qualitative Inquiry, 13(1), 3-29. https://doi/org/10.1177/1077800406294947.

Ellis, C., \& Bochner, A. (2003). Autoethnography, personal narrative, reflexivity: Research as subject. In N. K. Denzin \& Y. S. Lincoln (Eds.), Collecting and interpreting qualititative materials (pp. 198-258). SAGE.

Flood, M. (2011). Involving men in efforts to end violence against women. Men and Masculinities, 14(3), 358-377.

Foucault, M. (1978) The history of sexuality Vol. I: An introduction. Pantheon.

Foucault, M. (1979). Discipline and punish: Birth of prisons. Vintage.

Gannon, S. (2006). The (Im)possibilities of writing the self-writing: French poststructural theory and autoethnography. Cultural Studies Critical Methodologies, 6(4), 474-495. 
Govender, D. (2015). Is domestic violence being policed in South Africa? Acta Criminologica: African Journal of Criminology \& Victimology, 28(2), 32-46. https://journals.co.za/content/crim/28/2/EJC185959

Govender, K. (2018). An exploration of the meanings Indian secondary school girls give to sexual risk in the context of HIV/AIDS (unpublished Masters thesis). University of KwaZulu-Natal, Durban, RSA.

Govender, P. (2008). Love and courage: A story of insubordination. Jacana Media.

Graaff, K., \& Heinecken, L. (2017). Masculinities and gender-based violence in South Africa: A study of a masculinities-focused intervention programme. Development Southern Africa, 34(5), 622-634. https://doi.org/10.1080/0376835X.2017.1334537.

Grosfoguel, R. (2013). The structure of knowledge in westernized universities: Epistemic racism/sexism and the four genocides/epistemicides of the long 16th century. Human Architecture: Journal of the Sociology of Self-Knowledge, 11(1), 73-90.

Jackson, A. Y., \& Mazzei, L. A. (2008). Experience and "I" in autoethnography: A deconstruction. International Review of Qualitative Research, 1(3), 299-318.

Jakobson, H. (2014). What's gendered in gender-based violence? An empirically grounded, theoretical exploration from Tanzania. Gender and Society, 28(4), 537-561.

Jewkes, R., Morrell, R., Hearn, J., Lundqvist, E., Blackbeard, D., Lindegger, G., Quale, M., Sikweyiya, Y. \& Gottzén, L. (2015). Hegemonic masculinity: Combining theory and practice in gender interventions. Culture, Health \& Sexuality, 17(sup. 2), 112-127. https://doi.org/10.1080/13691058.2015.1085094.

Jones, H. (2016). Living bodies of thought: The 'critical' in critical autoethnography. Qualitative Inquiry, 22(4), 228-237.

Jones, S. H. (2016). Living bodies of thought: The "critical" in critical autoethnography. Qualitative Inquiry, 22(4), 1-10.

Kempen, A. (2019a). Fighting gender-based violence: Teaching our children at home about respect could impact their future behaviour. Servamus Community-based Safety and Security Magazine, 112(11), 16-19. https://journals.co.za/content/journal/10520/EJC192cd797b0

Kempen, A. (2019b). Talk is cheap. . . we need to be serious about action plans to curb gender-based violence. Servamus Community-based Safety and Security Magazine, 112(11), 20-21. https://journals.co.za/content/journal/10520/EJC-192cd95c47

Kimmel, M. (2014). Men who love women: Pro-feminist masculinities in the millennium trilogy. Women's Studies International Forum, 46, 83-87. https://doi.org/10.1016/j.wsif.2013.12.007. 
Lorber, J. (2017). Feminisms. Wiley \& Company.

Lugones, M. (2016). The coloniality of gender. In W. Harcourt (Ed.), Handbook of gender and development (pp. 1-17). Palgrave Macmillan.

Marx, S., Pennington, J. L., \& Chang, H. (2017). Critical autoethnography in pursuit of educational equity: Introduction to the IJME special issue. International Journal of Multicultural Education, 19(1), 1-6.

Mitchell, C. (2016). Autoethnography as wide-angled lens on looking (inward and outward): What difference can this make to our teaching? In D. Pillay, I. Naicker, \& K. Pithouse-Morgan (Eds.), Academic autoethnographies: Inside teaching in higher education (pp. 175-190). Sense Publishers.

Morrell, R., Jewkes, R., Lindegger, G., \& Hamlall, V. (2013). Hegemonic masculinity: Reviewing the gendered analysis of men's power in South Africa. South African Review of Sociology, 44(1), 3-21. https://doi.org/10.1080/21528586.2013.784445.

Müller, B. M. (2019). Under Priscilla's eyes: State violence against South Africa's queer community during and after apartheid. Image \& Text: A Journal for Design, 33(1), 136. http://doi.org/10.17159/2617-3255/2018/n33a11.

Narayan, U. (1997). Dislocating cultures: Identities, traditions, and third-world feminism. Routledge.

Pillay, D., Naicker, I., \& Pithouse-Morgan, K. (2016). Writing academic autoethnographies: Imagination, serendipity and creative interactions. In D. Pillay, I. Naicker, \& K. Pithouse-Morgan (Eds.), Academic autoethnographies: Inside teaching in higher education (pp. 1-18). Sense Publishes.

Pithouse-Morgan, K., Naicker, I., \& Pillay, D. (2017). "Knowing what it is like”: Dialoguing with multiculturalism and equity through collective poetic autoethnographic inquiry. International Journal of Multicultural Education, 19(1), 125-143.

Rasool, S. (2017). Adolescent reports of experiencing gender-based violence: Findings from a cross-sectional survey from schools in a South African city. Gender and Behaviour, 15(2), 9109-9120. https://journals.co.za/content/journal/10520/EJC-b4170923f

Reed-Danahay, D. (2017). Bourdieu and critical autoethnography: Implications for research, writing, and teaching. International Journal of Multicultural Education, 19, 144-154.

Shefer, T. (2013). Critical reflections on contemporary responses to gender violence within public, political, health and research contexts. African Safety Promotion, 11(2), 1-13. https://journals.co.za/content/safety/11/2/EJC148764 
Shefer, T. (2016). Resisting the binarism of victim and agent: Critical reflections on 20 years of scholarship on young women and heterosexual practices in South African contexts. Global Public Health, 11(1-2), 211-223. https://doi.org/10.1080/17441692.2015.1029959.

Singh, S., Mabaso, B., Mudaly, R., \& Singh-Pillay, A. (2016). Policy for prevention of sexual assault on campus: Higher education students' perspectives. Alternation, 23(1), 113134.

Singh, S., Mudaly, R., \& Singh-Pillay, A. (2015). The what, who and where of female students' fear of sexual assault on a South African university campus. Agenda, 29(3), 97-105.

Szakolczai, A. (2009). Liminality and experience: Structuring transitory situations and transformative events. International Political Anthropology, 2(1), 141-172.

Taole, M. J. (2016). Learners' self-reports of exposure to violence in South African schools: A gendered reflection: Original contributions. African Safety Promotion, 14(1), $42-$ 61. https://journals.co.za/content/safety/14/1/EJC199561

Tilley-Lubbs, G. (2016). Critical autoethnography and the vulnerable self as researcher. In G. Tilley-Lubbs \& S. Calva (Eds.), Re-telling our stories: Imagination and practice (pp. 3-15). Sense Publishers.

Turner, V. (2017). The ritual process: Structure and anti-structure. Routledge.

United Nations general Assembly (1993) Declaration on the elimination of violence against women, Resolution 48/104 of 20 December 1993. 